\title{
Development of a Stimulation System for the Gustatory Eye-Blink Response in Humans
}

\author{
Ichiro Ashida, Yozo Miyaoka \\ Department of Health and Nutrition, Niigata University of Health and Welfare, Niigata, Japan \\ Email: asida@nuhw.ac.jp
}

How to cite this paper: Ashida, I. and Miyaoka, Y. (2016) Development of a Stimulation System for the Gustatory Eye-Blink Response in Humans. Journal of Behavioral and Brain Science, 6, 387-392. http://dx.doi.org/10.4236/jbbs.2016.610037

Received: July 22, 2016

Accepted: August 21, 2016

Published: August 24, 2016

Copyright $(92016$ by authors and Scientific Research Publishing Inc. This work is licensed under the Creative

Commons Attribution International License (CC BY 4.0).

http://creativecommons.org/licenses/by/4.0/

\begin{abstract}
An inexpensive stimulation system for recording eye-blink responses elicited by taste stimuli has been developed using a manually controlled syringe and tasimetric sensor. The system requires neither an intra-oral device nor clamping of the head and tongue for natural eye-blink responses. The data recorded by the system have a high temporal resolution that is likely to be sufficient for the analysis of eye-blink responses based on video recordings.
\end{abstract}

\section{Keywords}

Eye-Blink, Taste Liquid, Stimulation Device, Tasimetric Sensor, Human

\section{Introduction}

Taste stimuli applied to the tongue can elicit facial responses in humans [1] [2]. The authors have previously reported that solutions of the four basic tastes and several commercial confections can also elicit eye-blink responses [3] [4]. Among the eye-blink parameters, the latency of the eye-blinks is particularly important for providing an estimate of the conduction path and the central processing of eye-blinks. In these experiments, the analysis of eye-blink parameters was based on video movies taken using commercially available cameras, with temporal resolutions ranging from 17 to $67 \mathrm{~ms}$.

For calculating latency, the stimulation time and the time when the eye-blink started must be recorded synchronously. A number of recording systems that can accurately identify these two time points have been developed for humans and animals over the last half-century. For humans, drinkometers have been developed and used to measure gustatory reaction time [5]-[8]. Some drinkometers use a system in which a signal pulse is generated at the moment when a stimulation liquid is poured from the orifice of a liquid delivery pipette and an electrical circuit between the body and pipette is closed. 
However, such a system is likely to be unsuitable for eye-blink experiments because the system requires the use of clamps on the head and tongue of the participants, which would affect the natural eye-blink responses. Other drinkometers use an intra-oral device to improve the temporal resolution [6], but these devices seem to be expensive, and it can be difficult to adjust and insert the intra-oral device for a large number of participants.

This study aimed to develop an inexpensive stimulation system, without the use of an intra-oral device or the hard clamping method, to record the natural eye-blink responses elicited by taste stimuli.

\section{Materials and Methods}

\subsection{Stimulation}

Figure 1 shows the stimulation-recording system developed. A silicon tube (i.d.: 3.2 $\mathrm{mm}$ ) was connected to a needleless plastic syringe $(20 \mathrm{ml})$ to provide the stimulation liquid ("a" in Figure 1) through a three-way stopcock ("b"). One of the branches led to the stimulation site, and the other branch was connected to a water-resistant tasimetric sensor ("c"). Changes in the hydraulic pressure detected by the sensor were recorded and stored on a Power $\mathrm{Lab}^{\oplus}$ system.

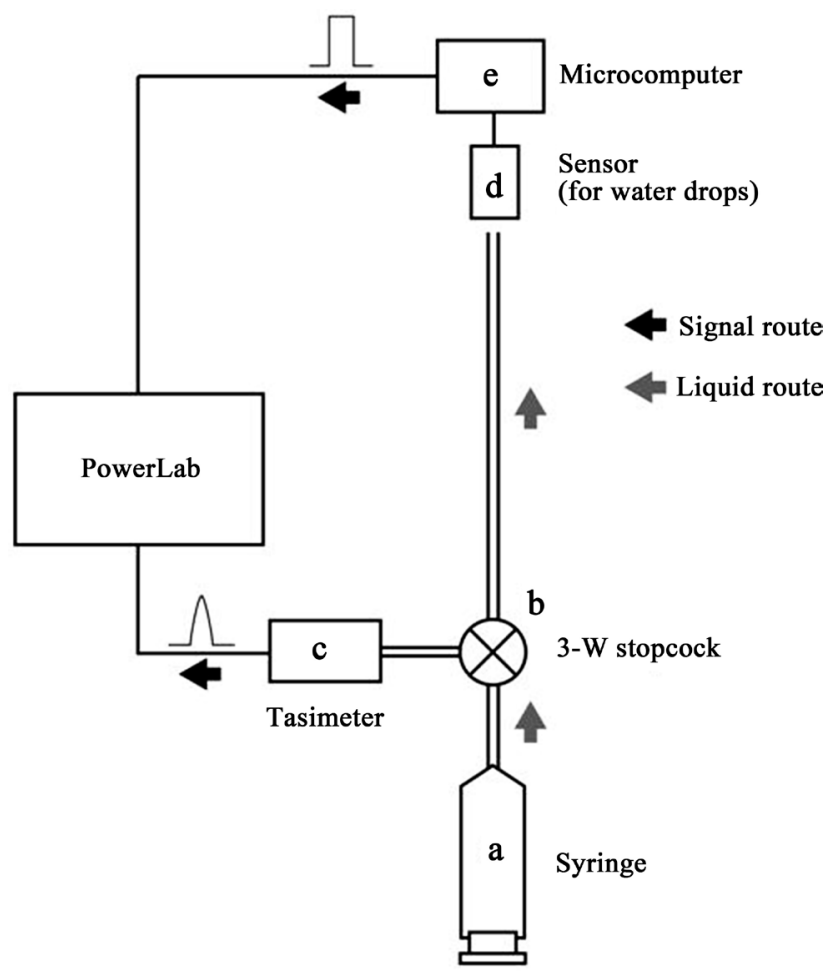

Figure 1. The developed stimulation-recording system. "a", A plustic syringe; "b", a three-way stopcock; "c", a water-resistant tasimetric sensor; "d", a sensor for detecting liquid drops; "e", A microcomputer for generating rectangular pulses. "a-d" are connected with silicon tubes. 


\subsection{Recording}

The injection of the stimulation liquid from the end of the silicon tube ("d" in Figure 1) was recorded using a sensor for detecting liquid drops to evaluate the temporal accuracy of the system. The sensor was joined to a microcomputer ("e"), and a computer program for generating rectangular pulses was developed using the Arduino ${ }^{\circledR}$ script. The pulses, synchronized with the liquid injections, were recorded and stored on the PowerLab ${ }^{\circledast}$ system.

\subsection{Procedures}

The inside of the stimulation device (including a syringe, tasimetric sensor, and three silicon tubes) was enclosed and filled with stimulation liquid, except at the stimulation site. Thus, the two signals (i.e., the hydraulic pressure and liquid injection pulse) were expected to be transmitted to the recorder almost simultaneously. Fifty recordings were conducted using the developed system with water as the stimulus to verify the transmission. Ten recordings of "very low pressure" $(<1.0 \mathrm{kPa})$ were not used for the analysis because these signals were too small and flat to distinguish from the baseline. To confirm the effects of the intensity of the syringe push, the delays between the starting point of the hydraulic pressure change and liquid injection were recorded. Further, the recorded delays were classified into two groups based on the intensity of the hydraulic pressure (the threshold for the two groups was set at $2.5 \mathrm{kPa}$, which was determined from the results of our preliminary experiments). The Student's t-test was used to examine the significance of the differences, with a $\mathrm{P}<0.05$ considered significant.

\section{Results and Discussion}

Some gustatory stimulation systems in previous reports [7]-[9] required hard clamps on the head and tongue to establish strict positioning for electrical circuits, but these clamps may disturb the participant's natural eye-blinks. The tongue of the participant was located at "d" in Figure 1 in the actual (human) experiments. The stimulation site of the silicon tube was held in the participant's mouth without any clamping devices in the developed system because the record of the hydraulic pressure was used as a synchronized signal for the injection of the stimulation liquid.

Figure 2 shows sample data recorded by the new system. The delay between the start of the hydraulic pressure change ("a" in Figure 2) and the liquid injection ("b") was $132.6 \mathrm{~ms}$ in this record. Figure 3 summarizes the results of the 40 trials that were conducted. The average delays for the lower and higher pressures were $133.2 \pm 7.1 \mathrm{~ms}(\mathrm{n}=$ $17)$ and $134.5 \pm 7.1 \mathrm{~ms}(\mathrm{n}=23)$, respectively. No significant difference between the two average delays was observed $(\mathrm{P}=0.56)$. The standard deviations (SDs) of the delays, 7.1 ms for both, were probably caused by the following two situations. First, the manual pushing of the syringe resulted in inconsistent speed and power of the pushing among trials. Mechanically controlled pushing by console devices (e.g., electromagnetic valves) will further reduce SDs of the delays, although the devices will a larger cost for the system. The fact about the homogeneity between the two average delays (Figure 3 ) suggests 


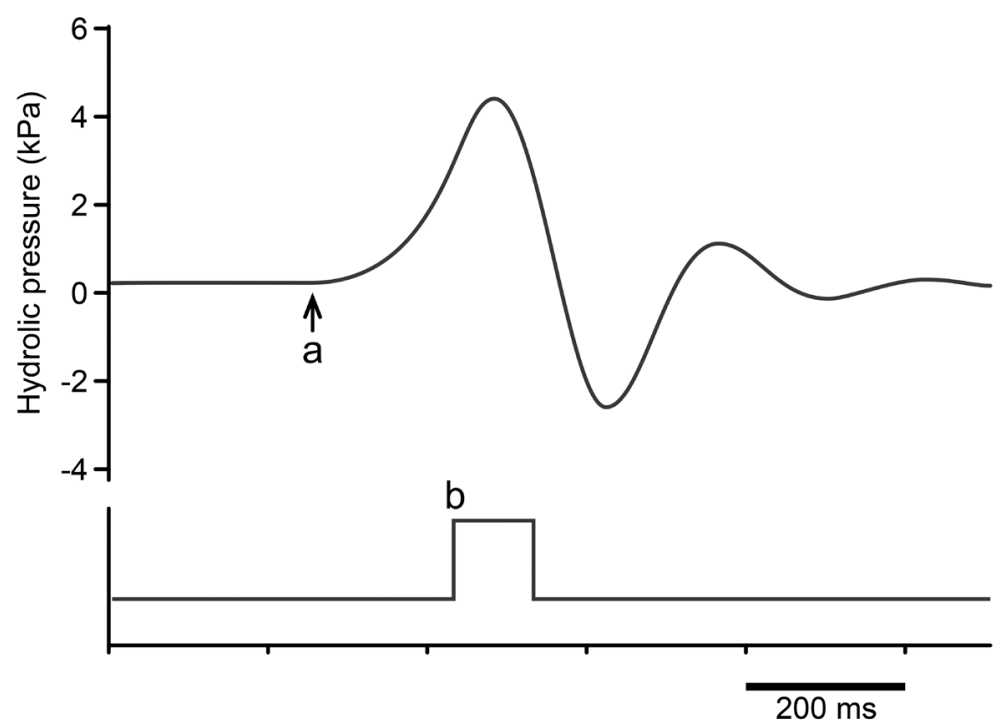

Figure 2. Sample data recorded by the developed system. Upper trace shows the changes in the hydraulic pressure detected by the tasimetric sensor (" $c$ " in Figure 1). Lower trace shows the liquid detection by the drop sensor ("d" in Figure 1). "a", the start of the hydraulic pressure change; " $b$ ", the the liquid injection. A delay between the hydraulic pressure and liquid injection ("b"-"a") was $132.6 \mathrm{~ms}$ in the sample data.

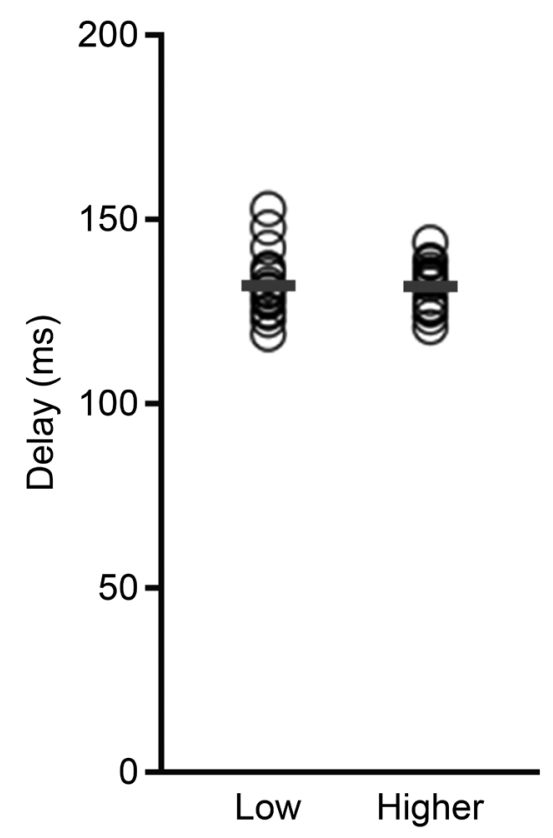

Figure 3. Delay between the hydraulic pressure and the liquid injection in low and higher pressures. Each circle and thick bar indicate each record and the average. The two averages are statistically homogeneous (Student's t-test, $\mathrm{P}=0.56)$.

that manual pushing is enough to accurately identify the stimulation time, whether the experimenters are not special trained for the pushing. Second, the pressure drop in the 
silicon tubes was likely to be involved in the delays [10].

The accuracy of the transmission (i.e., a SD of $7.1 \mathrm{~ms}$ ) is sufficient to allow the analysis of the eye-blink response based on video recordings because the sampling intervals in commercial video cameras (17 ms at minimum) are much longer than the SD value. However, when surface electromyograms (EMGs) of, for example, the orbicular is oculi muscle, are used as biological signals, the accuracy of the recorded stimulation time should be carefully considered because the sampling intervals of the EMGs usually range from 0.1 to $1.0 \mathrm{~ms}$.

\section{Conclusion}

A simple and inexpensive stimulation system for eye-blink responses elicited by taste stimuli was developed using a tasimetric sensor. The system requires neither an intra-oral device nor clamping of the head and tongue. The data recorded by the system have high temporal resolution (approximately $7 \mathrm{~ms}$ ) that is likely to be sufficient for the analysis of eye-blink responses based on video recordings.

\section{Acknowledgements}

This study was supported in part by a Grant-in-Aid for Scientific Research from the Ministry of Education, Science and Culture of Japan (No. 24501001).

\section{Conflict of Interest}

The authors declare no conflict of interest associated with this manuscript.

\section{References}

[1] Norgren, R. (1976) Taste Pathways to Hypothalamus and Amygdala. Journal of Comparative Neurology, 166, 17-30. http://dx.doi.org/10.1002/cne.901660103

[2] Steiner, J.E. (1979) Human Facial Expressions in Response to Taste and Smell Stimulation. Advances in Child Development and Behavior, 13, 257-295. http://dx.doi.org/10.1016/S0065-2407(08)60349-3

[3] Ashida, I., Tamaki, Y. and Miyaoka, Y. (2013) Eye Blink Responses to the Four Basic Taste Stimuli in Healthy Young Humans. Journal of Behavioral and Brain Science, 3, 379-384. http://dx.doi.org/10.4236/jbbs.2013.34038

[4] Ashida, I., Tamaki, Y. and Miyaoka, Y. (2013) Eye Blink Responses Elicited by Taste Stimuli Provided with Commercial Confectioneries. The Japanese Association for the Study of Taste and Smell, 20, 241-242.

[5] Matsuo, T. and Fukuda, K. (1996) A Development of Automatic Analyzing System of Eyeblinks Recorded in the Video Image. Japanese Journal of Physiological Psychology and Psychohysiology, 14, 17-21. http://dx.doi.org/10.5674/jjppp1983.14.17

[6] Goto, T.K., Yeung, A.W., Suen, J.L., Fong, B.S. and Ninomiya, Y. (2015) High Resolution Time-Intensity Recording with Synchronized Solution Delivery System for the Human Dynamic Taste Perception. Journal of Neuroscience Methods, 245, 147-155. http://dx.doi.org/10.1016/j.jneumeth.2015.02.023

[7] Lester, B. and Halpern, B.P. (1979) Effect of Stimulus Presentation Duration on Gustatory Reaction Time. Physiology \& Behavior, 22, 319-324. 
http://dx.doi.org/10.1016/0031-9384(79)90093-3

[8] Yamamoto, T. and Kawamura, Y. (1981) Gustatory Reaction Time in Human Adults. Physiology \& Behavior, 26, 715-719. http://dx.doi.org/10.1016/0031-9384(81)90149-9

[9] Halpern, B.P. (1986) Constraints Imposed on Taste Physiology by Human Taste Reaction Time Data. Neuroscience \& Biobehavioral Reviews, 10, 135-151. http://dx.doi.org/10.1016/0149-7634(86)90024-2

[10] Rathakrishnan, E. (2012) Fluid Mechanics: An Introduction. 3rd Edition, PHI Learning Private Limited, New Delhi.

Submit or recommend next manuscript to SCIRP and we will provide best service for you:

Accepting pre-submission inquiries through Email, Facebook, LinkedIn, Twitter, etc. A wide selection of journals (inclusive of 9 subjects, more than 200 journals)

Providing 24-hour high-quality service

User-friendly online submission system

Fair and swift peer-review system

Efficient typesetting and proofreading procedure

Display of the result of downloads and visits, as well as the number of cited articles Maximum dissemination of your research work

Submit your manuscript at: http://papersubmission.scirp.org/ 